\title{
Accuracy of the diagnosis of malignant hyperthermia in hospital discharge records
}

\author{
Teeda Pinyavat ${ }^{1}$, Henry Rosenberg ${ }^{1,2^{*}}$, Barbara H Lang ${ }^{1}$, Cynthia A Wong ${ }^{3}$, Sheila Riazi ${ }^{4}$, Joanne Brady ${ }^{5}$, Lena Sun ${ }^{1}$, \\ Guohua Li ${ }^{5}$
}

From 33rd Annual Meeting of the European Malignant Hyperthermia Group (EMHG)

Würzburg, Germany. 15-17 May 2014

\section{Background}

In 1997, the International Classification of Diseases, $9^{\text {th }}$ Revision Clinical Modification (ICD-9CM) coding system introduced the code for malignant hyperthermia (MH) (995.86). The aim of the current study was to estimate the accuracy of coding for MH in hospital discharge records.

\section{Materials and methods}

A panel of anesthesiologists expert in $\mathrm{MH}$, reviewed medical records for patients with a discharge diagnosis of $\mathrm{MH}$ based on ICD-9 or ICD-10 codes from January 1, 2006 to December 31, 2008 at six tertiary care medical centers in North America. All cases were categorized as possible, probable, or fulminant $\mathrm{MH}$, history of $\mathrm{MH}$ (family or personal) or other.

\section{Results}

A total of 47 medical records were identified and reviewed by three experts. The mean age of patients was 40 years and $49 \%$ were male. A surgical procedure with general anesthesia was documented in $68 \%$ of patients. However, only $23.4 \%$ were judged to have had a possible, probable, or fulminant $\mathrm{MH}$ event. Dantrolene was given in $81 \%$ of $\mathrm{MH}$ cases. Family and personal history of $\mathrm{MH}$ accounted for $46.8 \%$ of cases. High fever without evidence of MH during admission accounted for $23.4 \%$, and in $6.4 \%$ cases the reason for the code was not apparent. All patients judged to have an incident $\mathrm{MH}$ event survived to discharge.

\section{Conclusions}

Medical record coding for MH typically includes both incident cases as well as a history of $\mathrm{MH}$. The positive

'Department of Anesthesiology, Columbia University College of Physicians and Surgeons, New York City, NY 10032, USA

Full list of author information is available at the end of the article predictive value of about $70 \%$ for $\mathrm{MH}$ in this study are consistent with other studies of ICD-9 accuracy in the US. However, epidemiologic studies based on coded diagnosis of $\mathrm{MH}$ should carefully distinguish between incident cases related to anesthesia, cases unrelated to anesthesia and diagnosis based on history only.

\section{Authors' details \\ ${ }^{1}$ Department of Anesthesiology, Columbia University College of Physicians and Surgeons, New York City, NY 10032, USA. ${ }^{2}$ Department of Medical Education and Clinical Research, Saint Barnabas Medical Center, Livingston, NJ 07039, USA. ${ }^{3}$ Department of Anesthesiology, Northwestern University Feinberg School of Medicine, Chicago, IL 60611, USA. ${ }^{4}$ Department of Anesthesiology, Toronto General Hospital, Toronto, M5G 2C4, Canada. ${ }^{5}$ Departments of Anesthesiology and Epidemiology, Columbia University College of Physicians and Surgeons, New York City, NY 10032, USA.}

Published: 18 August 2014

doi:10.1186/1471-2253-14-S1-A23

Cite this article as: Pinyavat et al:: Accuracy of the diagnosis of malignant hyperthermia in hospital discharge records. BMC Anesthesiology 2014 14(Suppl 1):A23.

Submit your next manuscript to BioMed Central and take full advantage of:

- Convenient online submission

- Thorough peer review

- No space constraints or color figure charges

- Immediate publication on acceptance

- Inclusion in PubMed, CAS, Scopus and Google Scholar

- Research which is freely available for redistribution 